\title{
O-Methylated Metabolite of 7,8-Dihydroxyflavone Activates TrkB Receptor and Displays Antidepressant Activity
}

\author{
Xia Liu ${ }^{a}$ Qi Qia Ge Xiaob Jingyu Lic Hongbo R. Luo ${ }^{c}$ Keqiang Yea \\ ${ }^{a}$ Department of Pathology and Laboratory Medicine, Emory University School of Medicine, and ${ }^{\mathrm{b} C e n t e r s ~ f o r ~ D i s e a s e ~}$ \\ Control and Prevention, Atlanta, Ga., and ${ }^{\mathrm{C}}$ Department of Pathology and Lab Medicine, Harvard Medical School and \\ Children's Hospital Boston, Boston, Mass., USA
}

\section{Key Words}

TrkB agonist - Brain-derived neurotrophic factor .

Synthetic derivatives · Antidepressant $\cdot$ Neurogenesis
7,8-DHF is orally bioavailable and can penetrate the brainblood barrier. The O-methylated metabolites are implicated in TrkB receptor activation in the brain.

Copyright $\odot 2013$ S. Karger AG, Basel

\begin{abstract}
7,8-Dihydroxyflavone (7,8-DHF) acts as a TrkB receptor-specific agonist. It mimics the physiological actions of brain-derived neurotrophic factor (BDNF) and demonstrates remarkable therapeutic efficacy in animal models of various neurological diseases. Nonetheless, its in vivo pharmacokinetic profiles and metabolism remain unclear. Here we report that 7,8-DHF and its O-methylated metabolites distribute in mouse brain after oral administration. Both hydroxy groups can be mono-methylated, and the mono-methylated metabolites activate TrkB in vitro and in vivo. Blocking methylation, using COMT inhibitors, diminishes the agonistic effect of TrkB activation by 7,8-DHF or 4'-dimethylamino-7,8-DHF, supporting the contribution of the methylated metabolite to TrkB activation in mouse brain. Moreover, we have synthesized several methylated metabolite derivatives, and they also potently activate the TrkB receptor and reduce immobility in both forced swim test and tail suspension test, indicating that these methylated metabolites may possess antidepressant activity. Hence, our data demonstrate that
\end{abstract}

\section{Introduction}

Brain-derived neurotrophic factor (BDNF) is a member of the neurotrophin family, and exerts its biological functions on neurons predominantly through the TrkB receptor tyrosine kinase $[1,2]$. Although $\mathrm{BDNF} / \mathrm{TrkB}$ signaling is traditionally thought of in terms of synaptic plasticity and neuroprotection $[3,4]$, accumulating evidence indicates that these molecules are also critical for antidepressant drug efficacy. Accumulating evidence supports the neurotrophin hypothesis in depression. For instance, antidepressant treatment induces BDNF mRNA expression, as well as autophosphorylation and activation of TrkB in the brain $[5,6]$, and the behavioral effects of antidepressants in the forced swim test (FST) are attenuated in mice with only one active BDNF allele $\left(\mathrm{BDNF}^{+/-}\right.$ mice), completely lacking BDNF specifically in forebrain or expressing a dominant negative form of TrkB (trkB. T1) $[6,7]$. Ablation of TrkB specifically in hippocampal

\section{KARGER}

E-Mail karger@karger.com

www.karger.com/pha
(C) 2013 S. Karger AG, Basel

0031-7012/13/0914-0185\$38.00/0
Keqiang Ye

Department of Pathology and Laboratory Medicine

Emory University School of Medicine

Atlanta, GA 30322 (USA)

E-Mail kye@emory.edu 
neural progenitor cells prevents chronic antidepressantinduced neurogenesis and renders the mice behaviorally nonresponsive to chronic antidepressant treatment [8]. Combined, these results suggest a model whereby chronic antidepressant treatment induces BDNF expression and long-term activation of $\operatorname{TrkB}$, leading to increased neurogenesis and an antidepressant effect [9-11].

We have recently reported that 7,8-dihydroxyflavone (7,8-DHF) acts as a TrkB agonist, which selectively binds to the extracellular domain of $\operatorname{TrkB}$, but not TrkA, and stimulates its dimerization and autophosphorylation [12]. Most recently, it has been shown that 7,8-DHF mimics BDNF and dampens the stressful event-induced development of the 'depressive' phenotype [13]. Interestingly, chronic treatment with 7,8-DHF enhances neurogenesis in the dentate gyrus and demonstrates robust antidepressant effects. In addition, blocking TrkB inhibits the antidepressant effect of 7,8-DHF [14]. These findings allow us to hypothesize that 7,8-DHF may exert its antidepressant effect by directly activating TrkB receptors in the hippocampus. Although it takes a few weeks for orally administrated 7,8-DHF to exert its antidepressant effect, subchronic intraperitoneal injection of 7,8DHF also significantly decreases immobility in FST. However, acute injection of 7,8-DHF has no effect on the latency of immobility [14]. Although oral administration or intraperitoneal injection of 7,8-DHF displays impressive therapeutic efficacy on various BDNF/TrkB-implicated neurological diseases in animal models, its in vivo pharmacokinetic profiles and metabolism remain unknown. Catechol-containing compounds usually have a short in vivo half-life; they are prone to be cleared in the circulatory system and undergo oxidation, glucuronidation, sulfation or methylation. For instance, apomorphine, which contains a catechol group, is a nonnarcotic morphine derivative that acts as a potent dopaminergic agonist. Apomorphine metabolism occurs through several enzymatic pathways, including $\mathrm{N}$-demethylation, sulfation, glucuronidation, and catechol-O-methyltransferase (COMT)-catalyzed oxidation as well as by nonenzymatic oxidation [15]. COMT is involved in the inactivation of the catecholamine neurotransmitters. The enzyme transfers a methyl group to the catecholamine from the methyl donor, S-adenosyl methionine. The compounds with a catechol structure, like catechol estrogens and catechol-containing flavonoids, are substrates of COMT.

The main objectives of this study are to explore the in vivo pharmacokinetics/metabolism of 7,8 -DHF and identify its main metabolites in the brain and its potential functions. In this report, we show that 7,8-DHF has a half-life of about $134 \mathrm{~min}$ in plasma after oral gavage of $50 \mathrm{mg} / \mathrm{kg}$ of the drug. 7,8-DHF and its O-methylated metabolites are detectable in mouse brain with $\mathrm{T}_{\max }$ at 10 $\mathrm{min}$ and $\mathrm{C}_{\max }$ of $70 \mathrm{ng} / \mathrm{ml}$. Interestingly, the methylated metabolite swiftly activates TrkB in primary neurons and mouse brain. In addition, inhibition of methylation by blocking COMT reduces the TrkB stimulatory effect by 7,8-DHF. Also, the O-methylated metabolite and synthetic methoxy-flavone derivatives exhibit a prominent antidepressant effect.

\section{Experimental Procedures}

Cells, Reagents, and Mice

BDNF was from Roche. Anti-p-TrkB 817 was from Epitomics. Anti-TrkB antibody was from Cell Signaling. Wild-type C57BL/6 mice were bred in a pathogen-free environment in accordance with Emory Medical School guidelines. All chemicals not included above were purchased from Sigma. 7,8-DHF was purchased from TCI. The flavonoids were from Indofine (Hillsborough, N.J., USA): NMR spectrum (Bruker AV300K, $300 \mathrm{MHz}$ ), MS spectrum (Shimadzu LCMS), HPLC (PE, dual pumper, SPD detector, ODS$\mathrm{C} 18$ reverse phase, $254 \mathrm{~nm}, \mathrm{CH}_{3} \mathrm{CN}-\mathrm{H}_{2} \mathrm{O}-0.1 \%$ TFA). PhosphoTrkB Y816 antibody was raised against [H]-CKLQNLAKASPVpY-LDILG-[OH] (aa 806-822) (EM437 and EM438) as rabbit polyclonal antibody at Covance. The antiserum was purified by affinity column chromatography. This phospho-TrkB was utilized for immunoblotting and immunostaining the brain sections [14]. Mouse monoclonal anti-TrkB (BD Biosciences, San Jose, Calif., USA) was used for immunostaining. p-Akt 473 Sandwich ELISA was from Cell Signaling. Anti-phospho-Akt-473, anti-Akt, and anti-phospho-Erk1/2 antibodies were from Cell Signaling.

\section{Primary Rat Cortical Neuron Culture}

Cortical primary neurons were dissected from an E18 embryo and cultured, and the cortex was extirpated, cross-chopped and suspended by gently pipetting for separation in DMEM containing $5 \%$ fetal calf serum and $5 \%$ horse serum. The cell suspension was then centrifuged at $250 \mathrm{~g}$ for $5 \mathrm{~min}$. This operation was repeated again. Cells were seeded into polyethyleneimine-coated $10-\mathrm{cm}$ dishes and 12-well plates including coated coverslips and incubated at $37^{\circ} \mathrm{C}$ in $5 \% \mathrm{CO}_{2} / 95 \%$ air. After $3 \mathrm{~h}$, culture medium was changed to Neurobasal containing B-27 supplement (Invitrogen) and incubated for 4 days. For maintenance, half the medium was changed to fresh Neurobasal/B-27 every 4 days. After 1 week, the cultured neurons were used in drug treatment experiments.

\section{Forced Swim Test}

The FST assay is routinely performed in our lab. The experiment was conducted as previously described [14]. Adult male mice (2-3 months old) were randomly submitted to an FST without a preswim. Saline and methylated derivatives $(5 \mathrm{mg} / \mathrm{kg}, 250 \mu \mathrm{l})$ were orally administrated by gavage for 21 days. The mice were allowed to adapt to the test room for 2 days. They were placed in a clear 
glass cylinder with a diameter of $16 \mathrm{~cm}$, half-filled with clear water at $24^{\circ} \mathrm{C}$ (water depth of $14 \mathrm{~cm}$, and the mice were not allowed to reach the bottom of the cylinder; water was changed after each mouse) for a total of 6 min (with 2 min of preswim), and immobility was recorded during the last $4 \mathrm{~min}$ by an investigator blind to the genotype and treatment.

\section{Tail Suspension Test}

Among 3 well-established behavioral assays [FST, tail suspension test (TST), and learned helplessness] to examine the antidepressant effect, TST is a well-accepted and easy depression-like behavioral experimental paradigm [16]. Briefly, adult male mice (2-3 months old) were treated with saline and methylated derivatives $(5 \mathrm{mg} / \mathrm{kg})$ via oral gavage for 21 days. The total duration of immobility induced by tail suspension was measured according to the method described [17]. After chronic drug treatment, both acoustically and visually isolated mice were suspended $50 \mathrm{~cm}$ above the floor by adhesive tape placed approximately $1 \mathrm{~cm}$ from the tip of the tail. Mice were considered immobile only when they hung passively and completely motionless. Immobility time was manually recorded during a 6-min period by an experienced observer. The observer was in the room where experiments were performed and was blind to the condition of the animals.

Neurogenesis Analysis in TrkB Agonist-Treated Hippocampus

Adult male mice (2-3 months old) were orally administered with saline, compound $\mathrm{C}, \mathrm{D}$ and 7-methoxy-8-hydroxyflavone (H428; $5 \mathrm{mg} / \mathrm{kg}$ ) for 21 days. Then BrdU (50 mg/kg) was intraperitoneally injected. Within $2 \mathrm{~h}$, the mice were perfused with $4 \%$ paraformaldehyde. Immunohistochemical staining was performed on formalin-fixed paraffin-embedded sections. Sections of the brain were cut, deparaffinized in xylene, and rehydrated in graded alcohols. The slides were boiled in $10 \mathrm{mmol} / \mathrm{l} \mathrm{citric}$ acid ( $\mathrm{pH} \mathrm{6.0)}$ for 10 min, followed by incubation in $2 \mathrm{~N} \mathrm{HCl}$ for $10 \mathrm{~min}$ at room temperature. The slides were then permeabilized and blocked with $1 \%$ BSA in $0.2 \%$ PBS Tween 20. The incorporated BrdU was stained using anti-BrdU-FITC (Abcam, USA, $1: 50$ ) at $4^{\circ} \mathrm{C}$ overnight. After three washes in PBS, the cells were stained with DAPI for another $10 \mathrm{~min}$ at room temperature. The slides were finally mounted with AquaMount (Lerner Laboratories, USA) containing 0.01\% 1,4-diazobicyclo $(2,2,2)$ octane and examined under a fluorescent microscope.

\section{Immunohistochemistry Staining}

Brain tissues were fixed in $4 \%$ paraformaldehyde overnight followed by paraffin embedding.

Sections of $6 \mu \mathrm{m}$ were cut. For immunohistochemical staining, brain sections were deparaffinized in xylene and rehydrated in graded alcohols. Endogenous peroxidase activity was blocked by $3 \%$ hydrogen peroxide for $5 \mathrm{~min}$ and all slides were boiled in 10 $\mathrm{mmol} / \mathrm{l}$ sodium citrate buffer ( $\mathrm{pH}$ 6.0) for $10 \mathrm{~min}$. Phosphorylated TrkB816 and TrkB were detected using specific antibodies. Paraffin sections were deparaffinized in xylene and rehydrated gradient ethanol solution. Samples were boiled in $10 \mathrm{mmol} / \mathrm{l}$ sodium citrate buffer for $20 \mathrm{~min}$ to retrieve antigen. Brain sections were incubated with anti-TrkB (BD Biosciences) 1:50, p-TrkB 1:200 dilution at $4{ }^{\circ} \mathrm{C}$ overnight. After washing with PBS 3 times, TrkB and phosphorylated TrkB816 were detected using specific primary antibodies and the Zymed Histo-SP AEC kit. Slides were then counterstained with hematoxylin.

Methylation Mediates Biological Actions of 7,8-DHF
In vivo Pharmacokinetic Study (CRO by Cerep, Inc.)

Two-month-old male CD-1 mice (20-30 g) were obtained from Charles River Laboratories. The mice were divided into two groups: vehicle control and 7,8-DHF. 7,8-DHF was dissolved in water and $50 \mathrm{mg} / \mathrm{kg}$ of the dose was administered orally. Each animal was subjected to one blood draw and one brain collection. We had 3-, 10-, 30-, 60-, 120-, 240-, 360- and 480-min time points with 3 mice at each time point. For fasting, food but not water was withheld for at least 3-4 h. Following fasting, each mouse was weighed and the dose was calculated according to body weight. After administration of a test compound, food but not water was withheld for a further 1-2 h. Blood was collected via cardiac puncture. Blood aliquots $(300-400 \mu \mathrm{l})$ were collected in tubes coated with lithium heparin, mixed gently, then kept on ice and centrifuged at $2,500 \mathrm{~g}$ for $15 \mathrm{~min}$ at $4^{\circ} \mathrm{C}$ within $1 \mathrm{~h}$ of collection. The plasma was harvested and kept frozen at $-20^{\circ} \mathrm{C}$ until further processing. The brain sample was rinsed with cold saline, weighed, and kept on ice until further processing within $1 \mathrm{~h}$ of collection. Each brain was homogenized in $1.5 \mathrm{ml}$ cold PBS for $10 \mathrm{~min}$ on ice using Power Gen 125. The brain homogenate from each brain was then stored at $-20^{\circ} \mathrm{C}$ until further processing. The following are standard procedures for the HPLC-LC/MS/MS.

\section{Statistics}

Statistical analyses were performed using either Student's t test or one-way analysis of variance (ANOVA) followed by Tukey's multiple comparison tests versus controls by the computer program GraphPad Prism (GraphPad Software, USA). Results were expressed as mean \pm SEM and were considered as significant when $\mathrm{p}<0.05$.

\section{Organic Synthesis of Compound C and Compound D}

The compounds were synthesized following the methods described in our previous publication [14].

\section{Preparation of Compound 2}

To the solution of compound $1(2.0 \mathrm{~g}, 10.98 \mathrm{mmol}, 1.0 \mathrm{Eq})$ in $\operatorname{DMF}(20 \mathrm{ml}) \mathrm{Li}_{2} \mathrm{CO}_{3}(1.22 \mathrm{~g}, 16.47 \mathrm{mmol}, 1.5 \mathrm{Eq})$ and $\mathrm{BnBr}(2.25 \mathrm{~g}$, $13.18 \mathrm{mmol}, 1.2 \mathrm{Eq})$ were added. It was stirred at $60^{\circ} \mathrm{C}$ overnight. TLC and LC/MS showed that $\mathrm{BnBr}$ reacted with the two free $\mathrm{OH}$ groups. Two regioisomers and a bibenzylated product were formed. The $\mathrm{Li}_{2} \mathrm{CO}_{3}$ was filtered off and the solvent was removed under reduced pressure, after which water was added and extracted with EA 2 times. The organic phase was dried, filtered and concentrated. It was purified by a column chromatography for $1.1 \mathrm{~g}$ of crude product (containing some of the dibenylated product, ${ }^{1} \mathrm{HNMR}$ showed the desired product should be 70\%) (lot No. MC0707-43-1): ${ }^{1} \mathrm{HNMR}$ (400 MHz, DMSO- $\left.\mathrm{d}_{6}\right): \delta 12.56$ (br s, $\left.1 \mathrm{H}\right), 7.73(\mathrm{~d}, \mathrm{~J}=8.8 \mathrm{~Hz}, 1 \mathrm{H})$, $7.31-7.37(\mathrm{~m}, 9 \mathrm{H}), 6.69(\mathrm{~d}, \mathrm{~J}=9.2 \mathrm{~Hz}, 1 \mathrm{H}), 5.08(\mathrm{~s}, 1 \mathrm{H}), 5.00(\mathrm{~s}, 1 \mathrm{H})$, $4.95(\mathrm{~s}, 2 \mathrm{H}), 3.90(\mathrm{~s}, 1 \mathrm{H}), 3.88(\mathrm{~s}, 3 \mathrm{H})$, and $2.59(\mathrm{~s}, 3 \mathrm{H})$.

\section{Preparation of Compound 3}

To the solution of compound 2 ( $800 \mathrm{mg}, 2.06 \mathrm{mmol}, 1.0 \mathrm{Eq})$ in DCM (10 ml) 4-(pyrrolidin-1-yl)benzoic acid (550 mg, $2.88 \mathrm{mmol}$, $1.4 \mathrm{Eq})$, DCC (1,270 mg, $6.16 \mathrm{mmol}, 3.0 \mathrm{Eq})$ and DMAP (750 mg, $6.15 \mathrm{mmol}, 3.0 \mathrm{Eq})$ were added. It was stirred at room temperature overnight. TLC and LC/MS showed the reaction was complete. It was purified by column chromatography (PE:EA $=5: 1$ to $3: 1)$ for about $600 \mathrm{mg}$ of the desired product (lot No.: MC0707-044-A) [MS-ESI: calculated 445.2; found $446.2(\mathrm{M}+1)^{+}$]. 
Preparation of Compound 4

To the solution of compound 3 (500 mg, $1.12 \mathrm{mmol}, 1.0 \mathrm{Eq})$ in DMSO (10 ml) NaOH (225 mg, $5.62 \mathrm{mmol}, 5.0 \mathrm{Eq})$ was added. It was stirred at room temperature for $2 \mathrm{~h}$. TLC and LC/MS showed the reaction was completed. It was quenched with water and extracted with EA 3 times, then the combined EA phase was evaporated under reduced pressure after most EA was removed, water was added, the product was collected by filtration and dried to get $350 \mathrm{mg}$ of the desired product (lot No.: MC0707-045-1) [MS-ESI: calculated 445.2; found $\left.444.1(\mathrm{M}-1)^{-}, 446.2(\mathrm{M}+1)^{+}\right]$.

Preparation of Compound C

To the solution of compound $4(250 \mathrm{mg}, 0.56 \mathrm{mmol}, 1.0 \mathrm{Eq})$ in $\mathrm{AcOH}(10 \mathrm{ml}) \mathrm{H}_{2} \mathrm{SO}_{4}(0.1 \mathrm{ml})$ was added. It was refluxed for $1 \mathrm{~h}$. TLC and LC/MS showed the reaction was complete. The solvent was removed under reduced pressure, water was added, the product was collected by filtration, and washed with water and methanol to get $120 \mathrm{mg}$ of the desired product with 96\% HPLC purity (lot No.: MC0707-046-A): ${ }^{1} \mathrm{HNMR}\left(400 \mathrm{MHz}, \mathrm{DMSO}-\mathrm{d}_{6}\right): \delta 9.53$ $(\mathrm{s}, 1 \mathrm{H}), 7.96(\mathrm{~d}, \mathrm{~J}=8.8 \mathrm{~Hz}, 2 \mathrm{H}), 7.48(\mathrm{~d}, \mathrm{~J}=8.8 \mathrm{~Hz}, 1 \mathrm{H}), 7.16(\mathrm{~d}$, $\mathrm{J}=8.8 \mathrm{~Hz}, 1 \mathrm{H}), 6.66(\mathrm{~s}, 1 \mathrm{H}), 6.67-6.55(\mathrm{~d}, \mathrm{~J}=8.4 \mathrm{~Hz}, 2 \mathrm{H}), 3.94(\mathrm{~s}$, $3 \mathrm{H}), 3.34(\mathrm{~s}, 4 \mathrm{H}), 2.00$ (s, 4H) [MS-ESI: calculated 337.1; found $338.4(\mathrm{M}+1)^{+}$, HPLC: $\left.96 \%\right]$.

Preparation of Compound 6

To the solution of compound $5(12 \mathrm{~g}, 70 \mathrm{mmol}, 1.0 \mathrm{Eq})$ in DMF (180 ml) $\mathrm{Li}_{2} \mathrm{CO}_{3}$ (5.9 g, $70 \mathrm{mmol}, 1.0 \mathrm{Eq}$ ) was added. Then 1-(bromomethyl)benzene $(11.7 \mathrm{ml}, 1 \mathrm{~mol})$ was added dropwise. The solution was stirred at $60^{\circ} \mathrm{C}$ overnight under $\mathrm{N}_{2}$. TLC showed the reaction was complete. It was quenched with water and extracted with EA. The organic phase was dried, filtered, and concentrated. The residue was purified by column chromatography to get $5.4 \mathrm{~g}$ of the desired product (lot No.: MC0707-1-1, yield: 29\%): ${ }^{1} \mathrm{HNMR}$ (400 MHz, $\mathrm{CDCl}_{3}$ ): $\delta 12.51$ (br s, $\left.1 \mathrm{H}\right), 7.34-7.44(\mathrm{~m}, 5 \mathrm{H}), 7.26(\mathrm{~d}$, $\mathrm{J}=8.0 \mathrm{~Hz}, 1 \mathrm{H}), 6.53(\mathrm{~d}, \mathrm{~J}=8.8 \mathrm{~Hz}, 1 \mathrm{H}), 5.52(\mathrm{~s}, 1 \mathrm{H}), 5.24(\mathrm{~s}, 2 \mathrm{H})$, $2.56(\mathrm{~s}, 3 \mathrm{H})$.

\section{Preparation of Compound 7}

To the solution of compound $6(4.4 \mathrm{~g}, 1.0 \mathrm{Eq})$ in acetone (140 ml) $\mathrm{K}_{2} \mathrm{CO}_{3}(14.1 \mathrm{~g}, 6.0 \mathrm{Eq})$ and $(\mathrm{MeO})_{2} \mathrm{SO}_{4}(1.39 \mathrm{~g}, 0.5 \mathrm{Eq})$ were added. The reaction mixture was stirred at $5^{\circ} \mathrm{C}$ overnight. TLC showed the starting material and the desired product. It was quenched with water and extracted with EA. The organic phase was dried, filtered and concentrated. It was purified by column chromatography to get $1.1 \mathrm{~g}$ of the product (lot No.: MC0707-6-1, yield: $21 \%$ ): ${ }^{1} \mathrm{HNMR}\left(400 \mathrm{MHz}, \mathrm{CDCl}_{3}\right): \delta 12.56(\mathrm{~s}, 1 \mathrm{H}), 7.33-7.45$ $(\mathrm{m}, 6 \mathrm{H}), 6.51(\mathrm{~d}, \mathrm{~J}=8.8 \mathrm{~Hz}, 1 \mathrm{H}), 5.23(\mathrm{~s}, \mathrm{H}), 3.92(\mathrm{~s}, 3 \mathrm{H}), 2.56$ (s, $3 \mathrm{H})$.

Preparation of Compound 8

To the solution of compound $7(1.0 \mathrm{~g}, 1.0 \mathrm{Eq})$ in THF $(50 \mathrm{ml})$ t-BuOK (907.6 mg, $8.09 \mathrm{mmol}, 2.2 \mathrm{Eq}$ ) was added at $0^{\circ} \mathrm{C}$. Then the mixture was stirred for $30 \mathrm{~min}$ and 4 -(dimethylamino)benzoyl chloride (742.7 mg, $4.04 \mathrm{mmol}, 1.1 \mathrm{Eq}$.$) in THF (8 \mathrm{ml})$ was added. It was stirred for $3 \mathrm{~h}$. LC/MS showed the reaction was complete. It was quenched with water and extracted with EA. The organic phase was dried, filtered, and concentrated. The residue was purified by column chromatography to get 1.1 of the crude product (lot No.: MC0707-9-2) [MS-ESI: calculated 419.2; found 420.5 $\left.(\mathrm{M}+1)^{+}\right]$.

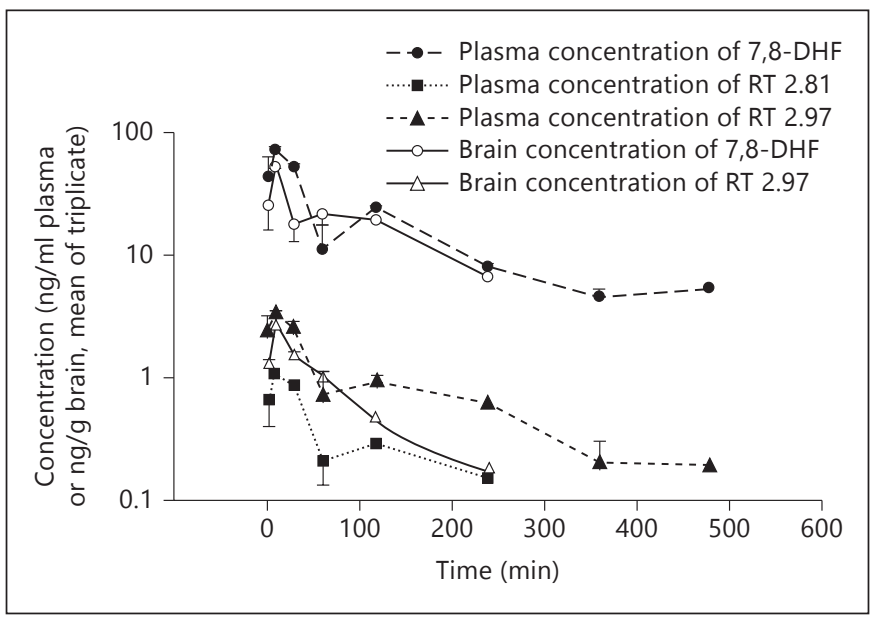

Fig. 1. In vivo pharmacokinetic profiling study of 7,8-DHF. Concentration-time profiles of 7,8-DHF and its metabolite 8-hydroxy-7-methoxyflavone (H428) and the isomer of 7-hydroxy-8-methoxyflavone (RT 2.92) in plasma and brain were analyzed by LC/MS/MS after oral administration $(50 \mathrm{mg} / \mathrm{kg})$ to mice with 7,8-DHF.

Preparation of Compound 9

To the solution of compound 8 (780 mg, $1.0 \mathrm{Eq})$ in DMSO ( $5 \mathrm{ml}) \mathrm{NaOH}$ (370 mg, 5.0 Eq) was added. It was stirred for $1 \mathrm{~h}$. $\mathrm{LC} / \mathrm{MS}$ showed the reaction was complete. The two batches were combined together and it was quenched with water. The $\mathrm{pH}$ was adjusted to 5-6. It was extracted with EA. The organic phase was concentrated and purified by column chromatography to get 550 mg of the crude product (lot No.: MC0707-23-1) [MS-ESI: calculated 419.2; found $\left.420.4(\mathrm{M}+1)^{+}\right]$.

Preparation of Compound D

To the solution of compound $9(500 \mathrm{mg}, 1.0 \mathrm{Eq})$ in $\mathrm{AcOH}(10$ $\mathrm{ml})$ concentrated $\mathrm{H}_{2} \mathrm{SO}_{4}(0.1 \mathrm{ml})$ was added. It was refluxed for 1 h. LC/MS showed the reaction was complete. It was quenched with water. It was extracted with EA. The organic phase was dried, filtered, and concentrated. The residue was purified by column chromatography to get about $110 \mathrm{mg}$ of compound D (lot No.: MC0707-28-1): ${ }^{1} \mathrm{HNMR}$ (400 MHz, DMSO-d 6 ): $\delta 10.46(\mathrm{~s}, 1 \mathrm{H})$, $7.89(\mathrm{~d}, \mathrm{~J}=9.2 \mathrm{~Hz}, 2 \mathrm{H}), 7.60(\mathrm{~d}, \mathrm{~J}=8.8 \mathrm{~Hz}, 1 \mathrm{H}), 6.96(\mathrm{~d}, \mathrm{~J}=8.8 \mathrm{~Hz}$, $2 \mathrm{H}), 6.85$ (d, J = 9.2 Hz, 2H), 6.69 (s, 1H), 3.94 (s, 3H), 3.03 (s, 6H) [MS-ESI: calculated 311.1; found $312.2(\mathrm{M}+1)^{+}$, HPLC: $\left.98.4 \%\right]$.

\section{Results}

\section{In vivo Pharmacokinetic Profiling and Metabolite Identification}

Catechol group-containing compounds, such as catecholamine neurotransmitters, levodopa, and flavonoids, are subjected to extensive metabolic modification that includes conjugation (glucuronidation, sulfation, and 
Table 1. In vivo pharmacokinetic parameters of 7,8-DHF (p.o. $50 \mathrm{mg} / \mathrm{kg}$ )

\begin{tabular}{|c|c|c|c|c|c|c|c|c|}
\hline $\begin{array}{l}\text { Cerep compound ID } \\
\text { (dosed) }\end{array}$ & $\begin{array}{l}\text { Client compound ID } \\
\text { (dosed) }\end{array}$ & $\begin{array}{l}\text { Route of } \\
\text { administration }\end{array}$ & $\begin{array}{l}\text { Dose } \\
\mathrm{mg} / \mathrm{kg}\end{array}$ & & & & & \\
\hline $100002126-1$ & 7,8-DHF & p.o. & 50 & & & & & \\
\hline $100002126-1$ & 7,8-DHF & mice & 10 & 70 & 134 & 6,500 & 7,515 & 7 \\
\hline
\end{tabular}

Pharmacokinetic parameters were derived from the noncompartmental model using WinNonlin 5.2.

$\mathrm{T}_{\max }=$ Time of maximum observed concentration; $\mathrm{C}_{\max }=$ concentration corresponding to $\mathrm{T}_{\max } ; \mathrm{T}_{1 / 2}=$ elimination half-life; $\mathrm{AUC}_{\text {last }}=$ area under the concentration-time curve from the time of dosing to the time of last observation that is greater than the limit of quantitation; $\mathrm{AUC}_{\mathrm{Inf}}=$ area under the concentration-time curve from the time of dosing, extrapolated to infinity; terminal point $=$ number of observations used to calculate the terminal slope.

${ }^{1}$ Linear/log trapezoidal method was used for AUC calculation.

Table 2. In vitro Caco-2 permeability assay for 7,8-DHF and $4^{\prime}$-DMA-7,8-DHF

\begin{tabular}{|c|c|c|c|c|c|c|}
\hline Client ID & $\begin{array}{l}\text { Test conc. } \\
\mu \mathrm{mol} / 1\end{array}$ & $\begin{array}{l}\text { Assay } \\
\text { duration, h }\end{array}$ & $\begin{array}{l}\text { Mean } \mathrm{A} \rightarrow \mathrm{B} \\
\mathrm{P}_{\text {app }}, 10^{-6} \mathrm{~cm} \cdot \mathrm{s}^{-1}\end{array}$ & $\begin{array}{l}\text { Mean } B \rightarrow A \\
P_{\text {app }}, 10^{-6} \mathrm{~cm} \cdot \mathrm{s}^{-1}\end{array}$ & $\begin{array}{l}\text { Efflux } \\
\text { ratio }^{1}\end{array}$ & Comment \\
\hline Ranitidine & 10 & 2 & 0.3 & 2.9 & 10.9 & low permeability, efflux \\
\hline Warfarin & 10 & 2 & 52.6 & 18.3 & 0.3 & high permeability control \\
\hline $4^{\prime}$-DMA-7,8-DHF & 10 & 2 & 0.9 & 3.1 & 3.6 & poor recovery $A$ to $B$ \\
\hline $7,8-\mathrm{DHF}$ & 10 & 2 & 1.5 & 1.7 & 1.2 & poor recovery $A$ to $B$ \\
\hline
\end{tabular}

$\mathrm{P}_{\mathrm{app}}=$ Apparent permeability.

${ }^{1}$ Efflux ratio $\left(\mathrm{R}_{\mathrm{E}}\right)>2$ indicates significant efflux activity, an indication of a potential substrate for PGP or other active transporters.

methylation) and oxidation, leading to their low bioavailability and poor pharmacokinetic profiles. Oral administration of 7,8-DHF or its synthetic derivative $4^{\prime}$-dimethylamino-7,8-DHF (4'-DMA-7,8-DHF) evidently activates the TrkB receptor in mouse brain at 2 or $4 \mathrm{~h}$ and exhibits prominent antidepressant activity, which suggests a stimulatory effect on TrkB by either the compounds themselves or by their metabolites [14]. Therefore, we investigated 7,8 -DHF in vivo pharmacokinetic profiles (after oral administration) at a $50 \mathrm{mg} / \mathrm{kg}$ dosage, which is 10 -fold the widely used therapeutic dose. We chose this high dose in order to quantitatively obtain brain concentrations of the drug and its metabolites at late time points. Mouse plasma and brain samples were collected at different time points $(3,10,30,60,120,240,360$ and 480 $\mathrm{min}$ ), subjected to acetonitrile precipitation, and analyzed by HPLC-MS/MS. Several major metabolites including 7-methoxy-8-hydroxy-flavone (7M8H-flavone) and two unknown peaks were detected in addition to the parent drug. The plasma 7,8-DHF concentration peaked at $10 \mathrm{~min}$ with $70 \mathrm{ng} / \mathrm{ml}$, and brain 7,8-DHF also peaked at $10 \mathrm{~min}$ with a concentration of $50 \mathrm{ng} / \mathrm{g}$ of brain. 7,8-DHF in plasma was still detectable even at $8 \mathrm{~h}(5 \mathrm{ng} / \mathrm{ml})$. However, in the brain, approximately $7 \mathrm{ng} / \mathrm{g}$ of 7,8-DHF was found at $4 \mathrm{~h}$ and it was below the quantitative limit at $6 \mathrm{~h}$. The 7-position methylated metabolite (7M8H-flavone) was detected as early as after $3 \mathrm{~min}$ in the plasma. Its concentration was maximal at $10 \mathrm{~min}$ with $1.0 \mathrm{ng} / \mathrm{ml}$, and it decreased to $0.2 \mathrm{ng} / \mathrm{ml}$ at $4 \mathrm{~h}$. It was below the quantitative limit at $6 \mathrm{~h}$. We failed to detect this metabolite in mouse brain at any time (fig. 1). The $\mathrm{T}_{1 / 2}$ for 7,8 -DHF is $134 \mathrm{~min}$ with $\mathrm{AUC}_{\text {last }}$ of $6,500 \mathrm{~min} \cdot \mathrm{ng} / \mathrm{ml}$ and $\mathrm{AUC}_{\text {Inf }}$ of 7,515 $\mathrm{min} \cdot \mathrm{ng} / \mathrm{ml}$. The in vivo pharmacokinetic profiles are summarized in table 1. In addition, we also monitored 7,8-DHF and Caco-2 permeability of its synthetic lead $4^{\prime}$-DMA-7,8-DHF, which is a good predictor of human oral bioavailability. The appar- 


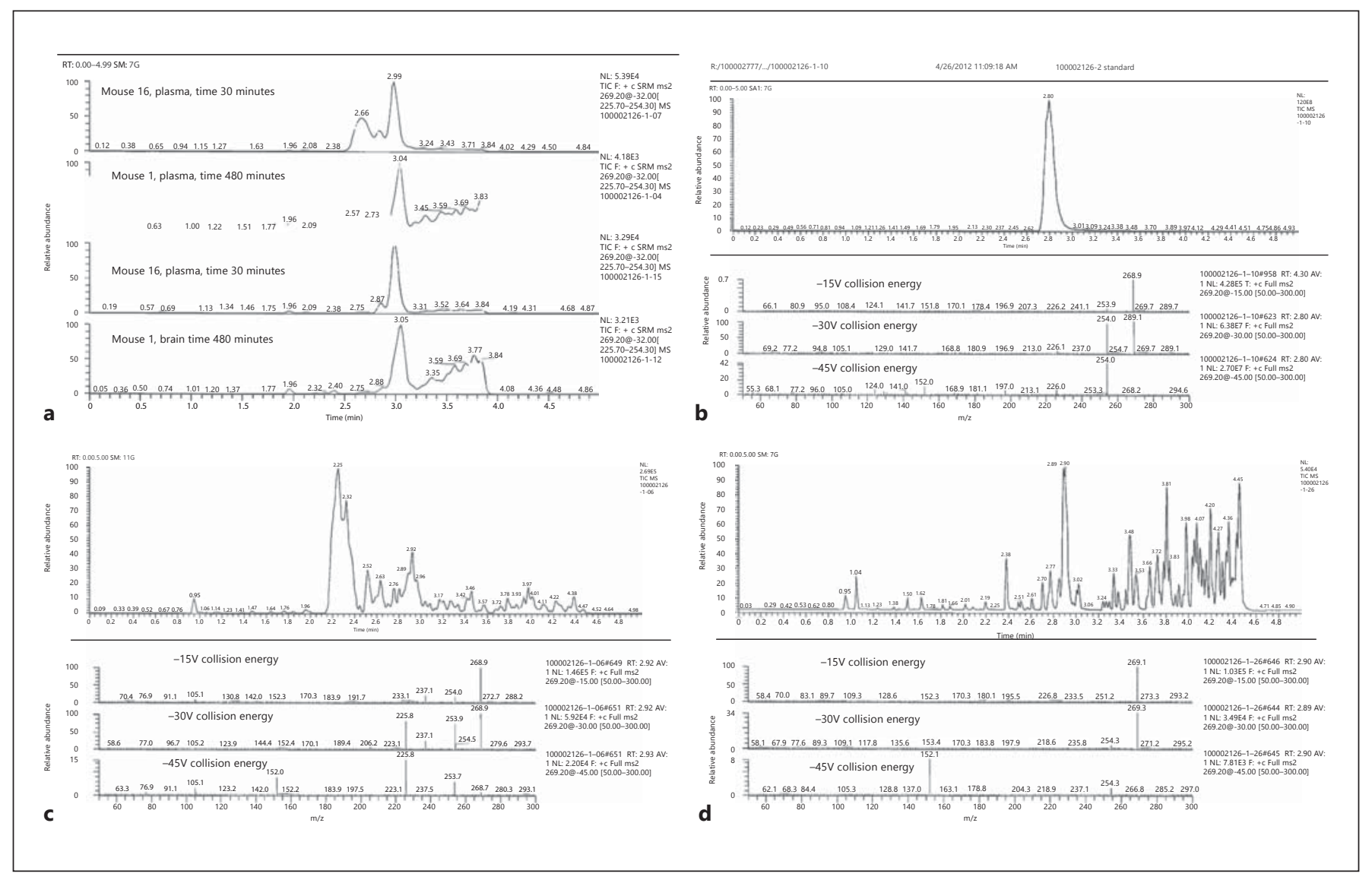

Fig. 2. Metabolite identification in mouse plasma. a Selected reaction monitoring of $269.2 \mathrm{~m} / \mathrm{z}$ precursor ion in plasma and brain samples after oral dosing of $50 \mathrm{mg} / \mathrm{kg} 7,8-\mathrm{DHF}$. b Product ion scan using $269.2 \mathrm{~m} / \mathrm{z}$ precursor ion of 8-hydroxy-7-methoxyflavone
(H428). c, d Product ion scan using $269.2 \mathrm{~m} / \mathrm{z}$ precursor ion of the spectrum peak of 2.92 (7-hydroxy-8-methoxyflavone) from plasma and brain samples. ent permeabilities $\mathrm{P}_{\text {app }}$ for these two compounds are listed in table 2. Notably, the addition of the dimethylamino group on the $4^{\prime}$-position of the $\mathrm{B}$ ring increased the efflux of the lead compound, indicating a reduction of oral bioavailability.

Identification of the Methylated Metabolites in Plasma and Mouse Brain

In order to identify the other metabolites, we conducted LC/MS/MS with the plasma samples at 30 min. Full scan HPLC-MS analysis was performed and total ion current chromatograms from the test and control samples were compared. Retention times, peak areas, and the respective MS spectra of the species detected in the test samples, but not in the control samples, were identified and recorded. The retention time on HPLC for the authentic metabolite $\mathrm{H} 428$ was 2.8 min. The identities of the compounds with retention times of 2.92 and 2.66 min remained unclear (fig. 2a). In order to get more information about the chemical structure of the additional peaks, a product ion scan was performed. The 2.66-min peak had a broad, uneven profile and its elution time was earlier than in the tandem MS analysis; also, no product ions were observed in the spectrum. Based on this observation and the fact that a similarly intense, broad peak was seen in the control plasma sample, the 2.66-min peak was attributed to the matrix itself and was not thought to be related structurally to 7,8 -DHF or H428. Since the product ion spectrum of the standard (H428) and the 2.92-min peak from numerous mouse samples were very similar, and the molecular weight was the same, 268 (m/z 269), we concluded that this peak represented the other methylated isomer, 7-hydroxy-8-methoxyflavone (fig. 2b-d). In 
addition to these two methylated metabolites, we also observed the extracted ion chromatogram at $431 \mathrm{~m} / \mathrm{z}$, which corresponds to the $\mathrm{M}+\mathrm{H}+176 \mathrm{~m} / \mathrm{z}$ glucuronidated product of 7,8-DHF in the plasma but not in the brain (online suppl. fig. 1; for all online suppl. material, see www.karger.com/doi/10.1159/000346920). Hence, 7,8DHF can be methylated as well as conjugated, by glucuronidation, in vivo after oral dosing of $50 \mathrm{mg} / \mathrm{kg}$ of 7,8-DHF in mice. 7,8-DHF and its methylated metabolites can penetrate the brain-blood barrier (BBB).

\section{The Metabolite, 7M8H-Flavone, Activates}

the TrkB Receptor in Primary Neurons and

Mouse Brain

To explore whether the methylated metabolite could activate the TrkB receptor in primary neurons, we compared the mono-methylated $\mathrm{H} 428$ and dimethylated 7,8DHF (D024) with their 4'-DMA-7,8-DHF counterparts. As we previously reported, $4^{\prime}$-DMA-7,8-DHF displayed more robust TrkB agonistic activity than 7,8-DHF. We made a similar observation for $4^{\prime}$-DMA-H428 versus H428. Interestingly, the dimethylated derivatives also somehow triggered TrkB activation (fig. $3 a, b$ ). BDNF was included as a positive control for validating TrkB activation in primary neurons by the lead compound (fig. 3b, lower panels). To assess whether the methylated H428 could trigger TrkB activation in mouse brain, we treated C57BL/6J mice with $5 \mathrm{mg} / \mathrm{kg}$ of various compounds via oral gavage. The brain samples were collected $2 \mathrm{~h}$ after drug treatment. Immunoblotting analysis demonstrated that both 7,8-DHF and H428 clearly activated the TrkB receptor compared to vehicle control. The dimethylated 7,8-DHF (D024) also elicited TrkB activation (p-TrkB Y816), but the effect was not as strong as that of the other two compounds (fig. 3c, top panel). However, p-TrkB 706 immunoblotting demonstrated that D024 elicited the strongest $\mathrm{p}$-TrkB signal (fig. $3 c, 2$ nd panel). The p-Akt ELISA assay showed that the downstream Akt signal was activated by these compounds as well (fig. 3c, bottom panel). We conducted the same experiments with $4^{\prime}$-DMA-7,8-DHF derivatives with oral dosing of $1 \mathrm{mg} / \mathrm{kg}$. We observed a similar trend of p-TrkB activation in brain lysates (fig. 3d, top panel). Both $4^{\prime}$-DMA7,8-DHF and its mono-methylated derivative potently activated Akt, whereas the dimethylated derivative failed to do so (fig. 3d, bottom panel). Therefore, the 7-methylated metabolite of 7,8-DHF activates TrkB signaling in primary neurons and mouse brain.

Methylation Mediates Biological Actions of 7,8-DHF
Inhibition of COMT Reduces TrkB Activation by

7,8-DHF or 4'-DMA-7,8-DHF

To ascertain whether COMT is responsible for the methylation of 7,8-DHF, we employed two COMT inhibitors that include tolcapone and entacapone, which are commonly used in the treatment of Parkinson's disease [18]. The optimal dose schedule for these two inhibitors has previously been extensively studied in rodents $[19,20]$. Following the experimental schemes, we pretreated mice with $30 \mathrm{mg} / \mathrm{kg}$ of the two inhibitors via oral gavage $1 \mathrm{~h}$ before 7,8-DHF or $4^{\prime}$-DMA-7,8-DHF administration, since this has been reported as a favorable dosage for COMT inhibitors [21]. Two hours after flavonoid treatment, we collected the brain samples and analyzed TrkB signaling. As expected, both 7,8-DHF and $4^{\prime}$-DMA-7,8-DHF obviously activated TrkB compared to vehicle control. Interestingly, entacapone and tolcapone alone clearly elevated $\operatorname{TrkB}$ phosphorylation compared to vehicle control (fig. $4 \mathrm{a}$, left panels lanes 4 and 7 vs. lane 1). Notably, in the presence of entacapone or tolcapone, TrkB activation by the flavonoids was not as strong as the agonists alone (lanes 5, 6 and 8, 9 vs. lanes 2,3), indicating COMT inhibitor pretreatment blocked TrkB activation by 7,8 -DHF or $4^{\prime}$-DMA-7,8DHF. The downstream p-Akt immunoblotting tightly correlated with the upstream p-TrkB status (fig. 4a, 3rd left panel). Since $30 \mathrm{mg} / \mathrm{kg}$ of COMT inhibitors alone triggered TrkB phosphorylation and shadowed the agonistic effect by two small agonists, we lowered the dose of the inhibitors to $10 \mathrm{mg} / \mathrm{kg}$ to reduce their effect on TrkB activation. We found entacapone at $10 \mathrm{mg} / \mathrm{kg}$ was still able to diminish the agonistic effect by $4^{\prime}$-DMA-7,8DHF, whereas tolcapone lost its inhibitory activity in suppressing TrkB phosphorylation by these two small agonists (fig. 4a, middle and right panels). p-Akt ELISA analysis also confirmed our observation in the immunoblotting assay. There are no significant changes between control versus 7,8-DHF or $4^{\prime}$-DMA-7,8-DHF in both the entacapone-treated and tolcapone-treated groups (fig. 4b). Hence, methylation of 7,8-DHF might mediate the agonistic effect of 7,8-DHF in mice.

\section{M8H-Flavone and Synthetic O-Methylated}

Derivatives Display Antidepressant Effects

To explore whether the methylated derivatives also possess the agonistic effect, we synthesized several $4^{\prime}$-position substitute derivatives and examined their TrkB stimulatory effect on primary neurons. The organic synthetic routes are summarized in figure $5 \mathrm{a}$. Oral administration of two compounds at a $1 \mathrm{mg} / \mathrm{kg}$ dosage robustly 
<smiles>O=c1cc(-c2ccccc2)oc2c(O)c(O)ccc12</smiles>

7,8-DHF<smiles>CN(C)c1ccc(-c2cc(=O)c3ccc(O)c(O)c3o2)cc1</smiles>

a

4'-DMA-7,8-DHF<smiles>COc1ccc2c(=O)cc(-c3ccccc3)oc2c1O</smiles>

8-Hydroxy-7-methoxyflavone<smiles>COc1ccc2c(=O)cc(-c3ccc(N(C)C)cc3)oc2c1O</smiles>

4'-DMA-8-H-7M-F<smiles>COc1ccc2c(=O)cc(-c3ccccc3)oc2c1OC</smiles>

7,8-Dimethoxyflavone<smiles>COc1ccc2c(=O)cc(-c3ccc(N(C)C)cc3)oc2c1OC</smiles>

4'-DMA-7,8-DMF b

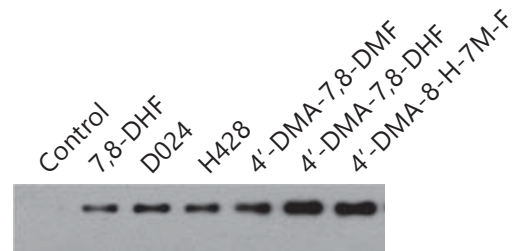

IB: anti-p-TrkB Y816

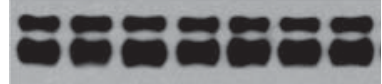

IB: anti-TrkB
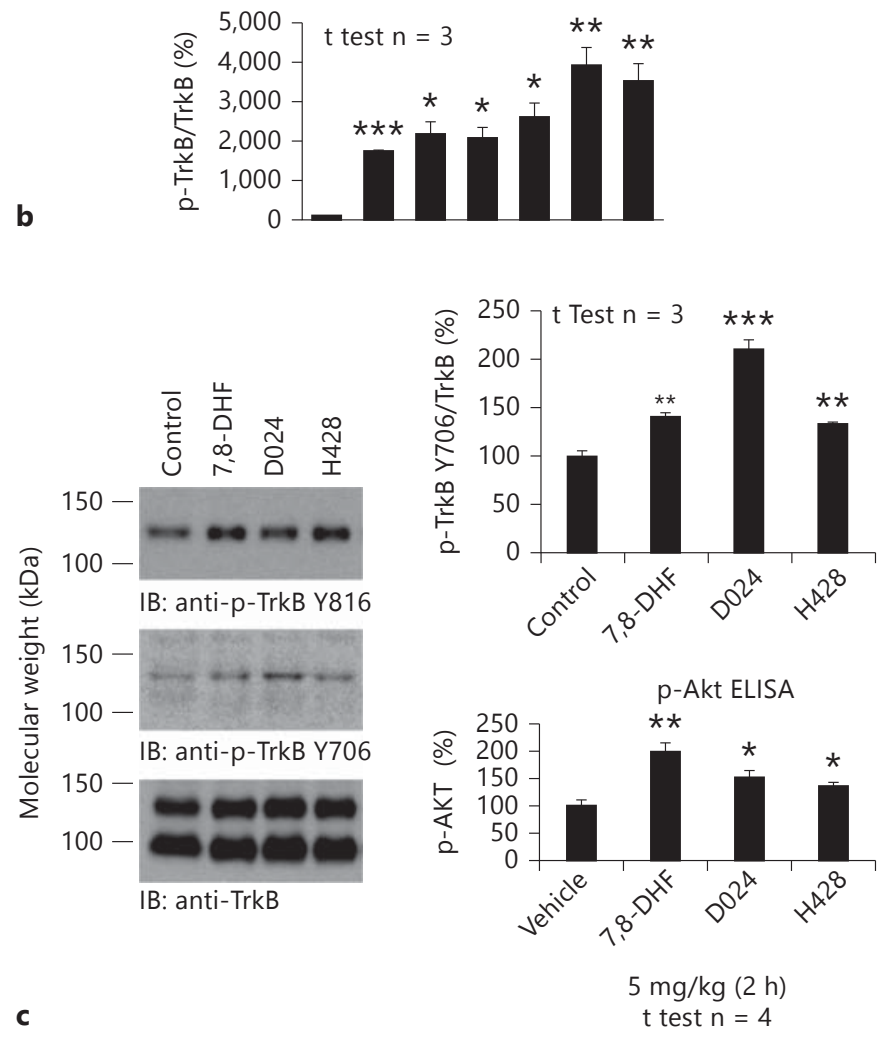
triggered TrkB activation in mouse brain $2 \mathrm{~h}$ after drug treatment (fig. 5b). FST and TST are well established behavioral assays used to examine antidepressant effects. We have shown that both 7,8-DHF and its lead compound $4^{\prime}$-DMA-7,8-DHF robustly decreased the immobility in FST after chronic treatment [14]. To investigate whether these methylated derivatives possess any antidepressant effect, we conducted a chronic experiment by consecutively treating the mice with $5 \mathrm{mg} / \mathrm{kg}$ of drugs for 21 days (orally, once a day). In an FST assay, all three compounds significantly reduced the immobility with H428 exhibiting the strongest effect (fig. 5c, left panel). In a TST assay, both H428 and compound C substantially decreased the immobility, whereas compound D lowered the immobility, but the reduction was not statistically significant (fig. 5c, right panel). Notably, acute drug treatment had no effect on immobility, which is different from traditional SSRI or tricyclic antidepressants (data not shown). Moreover, we monitored locomotor activity after 3 weeks of drug treatment, and found compound $\mathrm{D}$ significantly increased the locomotor activity compared to vehicle control or H428, compound C (fig. 5d). Presumably, compound D might reduce immobility by increasing the locomotor activity. Thus, the 7-methylated $\mathrm{H} 428$ and compound $\mathrm{C}$ activate the TrkB receptor and display a prominent antidepressant effect.

\section{M8H-Flavone and Synthetic O-Methylated}

Derivatives Activate TrkB and Enhance Neurogenesis in the Hippocampus

BDNF is capable of enhancing neurogenesis; intrahippocampal infusion of BDNF into the hippocampus of adult rats increases the production of new neurons [22] and chronic (but not acute) antidepressant administration increases BDNF expression and neurogenesis. To examine whether chronic treatment with the methylated derivatives regulates neurogenesis, we conducted a BrdU incorporation assay by intraperitoneally injecting

Fig. 3. The methylated metabolite $\mathrm{H} 428$ activates TrkB receptor in vitro and in vivo. a Chemical structures of 7,8-DHF and various methylated derivatives. b Methylated 7,8-DHF derivatives activate TrkB receptor in primary neurons. The primary cortical neurons (DIV12) from E17 rat embryos were treated with $500 \mathrm{nmol} / \mathrm{l}$ of various chemicals for $15 \mathrm{~min}$. The control was treated with the same volume of vehicle DMSO/PBS. The neuronal lysates were subjected to SDS-PAGE, followed by immunoblotting with anti-p-TrkB Y816 and anti-TrkB (cell signaling) (upper panels). BDNF, a positive control, and lead compound 4'-DMA-7,8-DHF activated TrkB receptor signaling pathways

Methylation Mediates Biological Actions of 7,8-DHF
BrdU $2 \mathrm{~h}$ before sacrificing the animals. We found 3 weeks of drug treatment, with both $\mathrm{H} 428$ and compound $\mathrm{C}$, significantly promoted neurogenesis compared to vehicle, whereas compound D also elevated neurogenesis but the result was not statistically significant (fig. 6a, b). Immunohistochemistry staining with $\mathrm{p}$-TrkB and total TrkB antibodies also demonstrated that both $\mathrm{H} 428$ and compound C strongly provoked TrkB phosphorylation in the dentate gyrus in the hippocampus. Nonetheless, the $\mathrm{p}-\mathrm{TrkB}$ signal by compound $\mathrm{D}$ was not as strong as those of $\mathrm{H} 428$ and compound $\mathrm{C}$ (fig. $6 \mathrm{c}$ ). Hence, chronic treatment with methylated derivatives enhanced $\operatorname{TrkB}$ activation and triggered neurogenesis in the hippocampus.

\section{Discussion}

In the current report, we show that 7,8-DHF can penetrate the $\mathrm{BBB}$ and its major metabolites in plasma are $\mathrm{O}$-mono-methylated and O-glucuronidated metabolites. In the brain, 7,8-DHF and one mono-methylated metabolite (7-hydroxy-8-methoxyflavone) are also detected. Interestingly, blockage of COMT with two different inhibitors reduces the TrkB stimulatory activity by 7,8 DHF or the lead compound $4^{\prime}$-DMA-7,8-DHF in mouse brain, indicating that the methylated metabolites contribute to TrkB receptor activation upon oral administration of 7,8-DHF. Interestingly, the methylated metabolite $\mathrm{H} 428$ activates the $\mathrm{TrkB}$ receptor in primary neurons and in mouse brain after oral administration, underscoring the observation that methylated metabolites trigger TrkB receptor activation. As expected, chronic treatment with the methylated metabolite H428 or its synthetic derivatives for 3 weeks significantly reduces the immobility in two types of antidepressant behavioral assays, which were accompanied with evident TrkB phosphorylation in the hippocampus and demonstrable neurogenesis.

in primary neurons (lower panel). c, d. 7,8-DHF and its methylated derivatives activate TrkB receptor in mouse brain. Twomonth-old C57BL/6J mice were treated with $5 \mathrm{mg} / \mathrm{kg}$ of 7,8DHF, H428, and D024 via oral gavage. Within $2 \mathrm{~h}$, mice were sacrificed and brain samples were extracted and analyzed by immunoblotting with anti-p-TrkB 816 antibody and by p-Akt monitoring ELISA (c). 4'-DMA-7,8-DHF and its methylated derivatives were administrated to the mice at $1 \mathrm{mg} / \mathrm{kg}$, the brain samples were prepared at $2 \mathrm{~h}$, and the brains were analyzed by immunblotting and p-Akt ELISA (d). ${ }^{*} \mathrm{p}<0.05$; ${ }^{* *} \mathrm{p}<0.01$; $* * * \mathrm{p}<0.001$. 


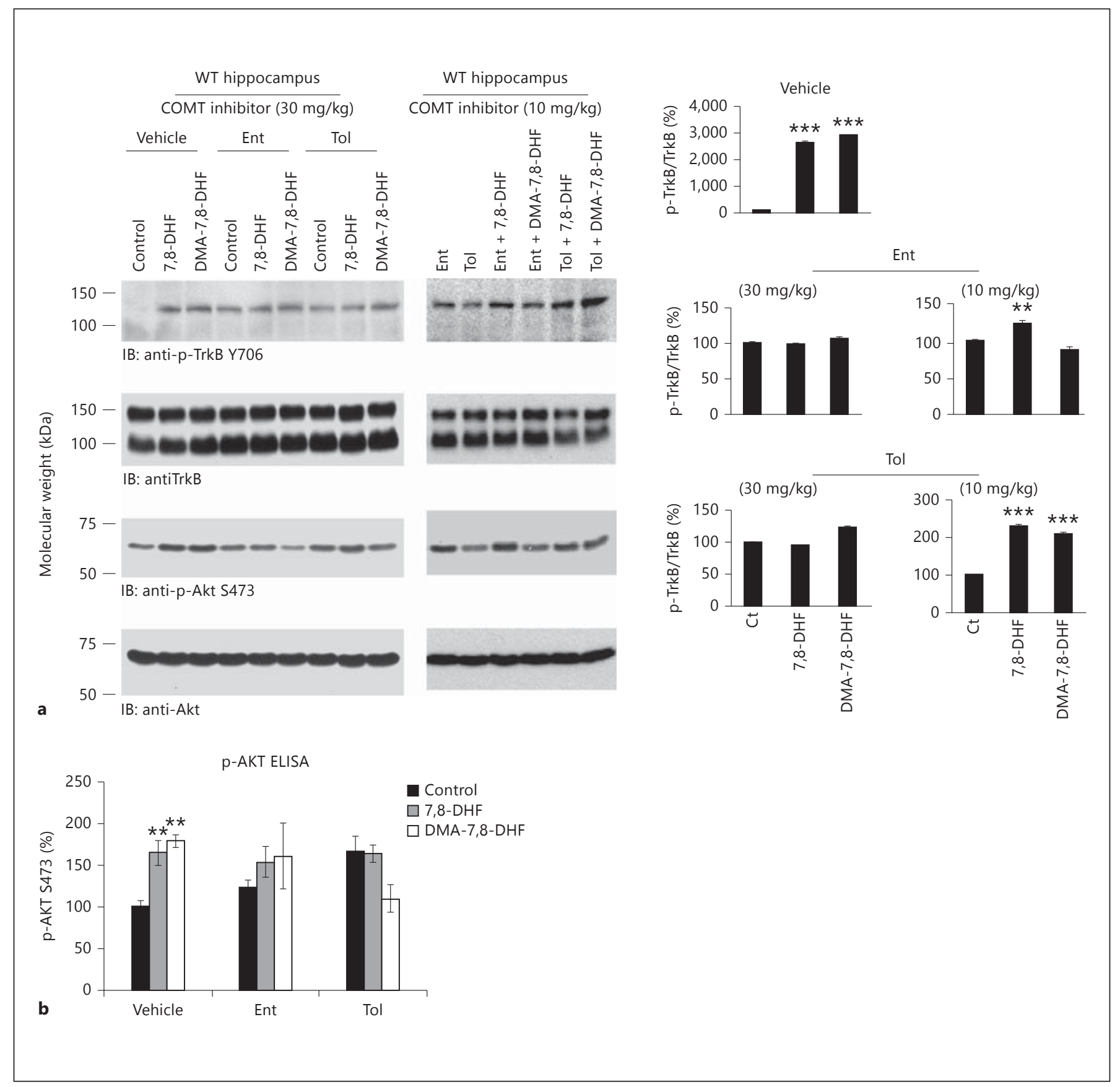

Fig. 4. Inhibition of methylation by COMT inhibitors reduces TrkB activation by 7,8-DHF or $4^{\prime}$-DMA-7,8-DHF. a COMT inhibitors decrease the agonistic effect of 7,8-DHF and $4^{\prime}$-DMA7,8-DHF on TrkB signaling. Two-month-old C57BL/6J mice were treated with $30 \mathrm{mg} / \mathrm{kg}$ of entacapone (Ent) or tolcapone (Tol) $1 \mathrm{~h}$ before $5 \mathrm{mg} / \mathrm{kg}$ of 7,8-DHF and $4^{\prime}$-DMA-7,8-DHF via oral gavage. Within $2 \mathrm{~h}$, mice were sacrificed and brain samples were extracted and analyzed by immunoblotting (left panels). Entacapone but not tolcapone decreases $\operatorname{TrkB}$ activation by $4^{\prime}$-DMA-7,8-DHF at a dose of $10 \mathrm{mg} / \mathrm{kg}$. To decrease the TrkB phosphorylation signals by COMT inhibitors, $10 \mathrm{mg} / \mathrm{kg}$ of COMT inhibitors were administered. The brain samples were analyzed as indicated above (middle panels). The quantification of $\mathrm{p}$-TrkB versus total TrkB was analyzed (right panels) (one-way ANOVA, $\mathrm{n}=3$; ${ }^{* *} \mathrm{p}<0.01$, *** $\mathrm{p}<0.001$ vs. control). b COMT inhibitors decrease the Akt activation by 7,8-DHF and $4^{\prime}$-DMA7,8 -DHF in brain at $30 \mathrm{mg} / \mathrm{kg}$. Quantitative analysis of brain samples by p-Akt ELISA. Data are presented as mean \pm SEM (one-way ANOVA, $\mathrm{n}=4$; ${ }^{* *} \mathrm{p}<0.01$ vs. control). WT $=$ Wildtype; $\mathrm{Ct}=$ control. 
<smiles>COc1ccc(C(C)=O)c(OC)c1O</smiles>

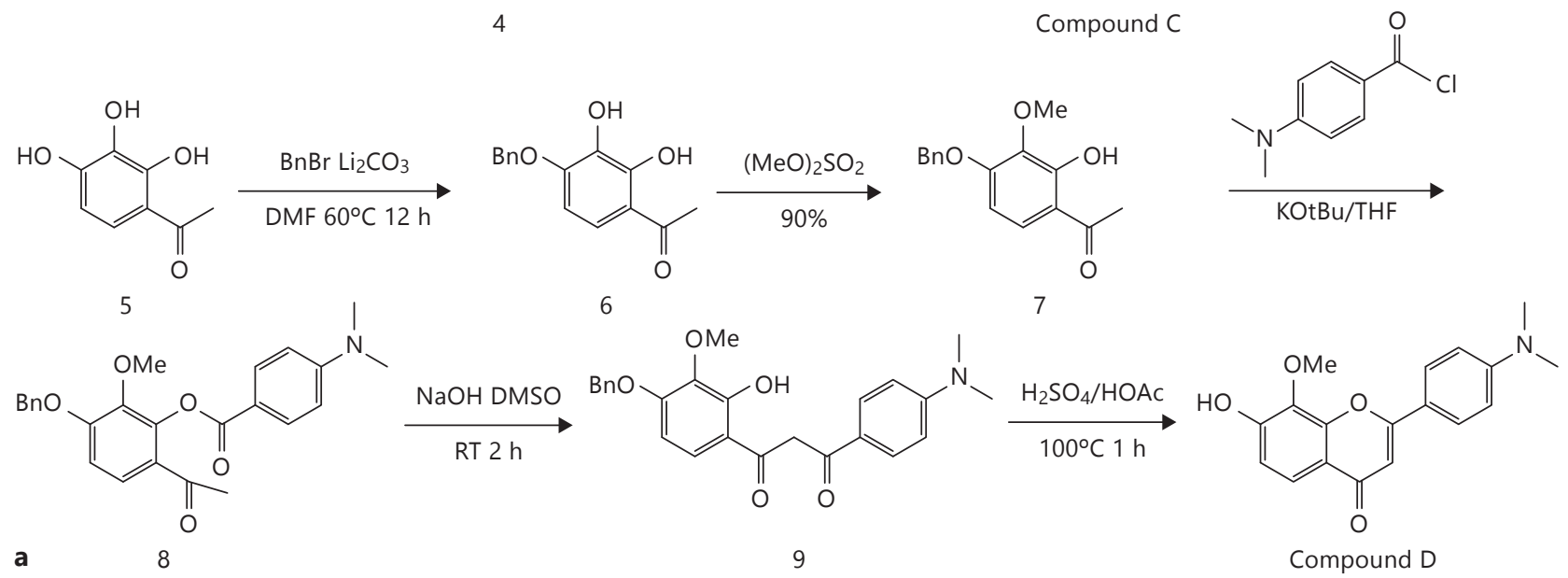

Fig. 5. Chronic treatment with methylated derivatives displays a robust antidepressant effect. a Organic synthesis of methylated derivatives of flavonoids.

These observations support the notion that the active methylated metabolite induces chronic TrkB activation and prominent neurogenesis, leading to a robust antidepressant effect.

Since oral administration of 7,8-DHF or its synthetic derivative $4^{\prime}$-DMA-7,8-DHF provokes TrkB activation at $1-2 \mathrm{~h}$ and the stimulatory effect is demonstrable even at $4 \mathrm{~h}$ in mouse brain, we investigated its in vivo pharmacokinetic profiles. The $\mathrm{C}_{\max }$ of 7,8-DHF in plasma peaked at $10 \mathrm{~min}$ with $70 \mathrm{ng} / \mathrm{ml}$, but it slowly decreased to $24 \mathrm{ng} / \mathrm{ml}$ at $4 \mathrm{~h}$, and even at $8 \mathrm{~h}, 5 \mathrm{ng} / \mathrm{ml}$ of 7,8-DHF was detected, indicating that it is orally bioavailable. Although its bioavailability is low, it is metabolized at a much slower pace when its concentration is low. On the other hand, both the methylated metabolite concentrations are relatively low compared to the parent 7,8-DHF, suggesting that glucuronidation but not methylation may be the main metabolism. Interestingly, the 8-methoxy-metabolite possesses a 148-min half-life versus 92 min for 7-methoxy-metabolite in plasma, indicating that 8-methoxy-7-hydroxyflavone is more metabolically stable than 8 -hydroxy-7-methoxyflavone (H428). In brain samples, 7,8-DHF also peaks at $10 \mathrm{~min}$ with about $52 \mathrm{ng} / \mathrm{g}$ of brain, and decreases to $18 \mathrm{ng} / \mathrm{g}$ at $30 \mathrm{~min}$, after which it remains relatively stable until $240 \mathrm{~min}(7 \mathrm{ng} / \mathrm{g})$. Surprisingly, the 7-methoxy-metabolite (H428) is below the limit of quantification in the brain, whereas the 8-methoxy-metabolite is observable as early as $3 \mathrm{~min}$ after oral administration and detectable even at $240 \mathrm{~min}$ (fig. 1). Conceivably, if the methylated metabolites contribute to the in vivo TrkB agonistic effect by 

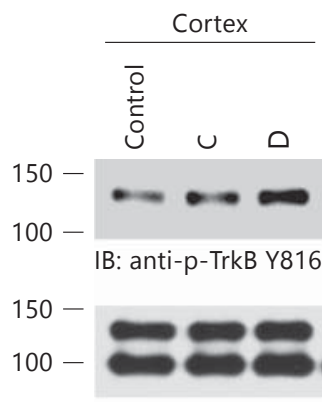

IB: anti-TrkB
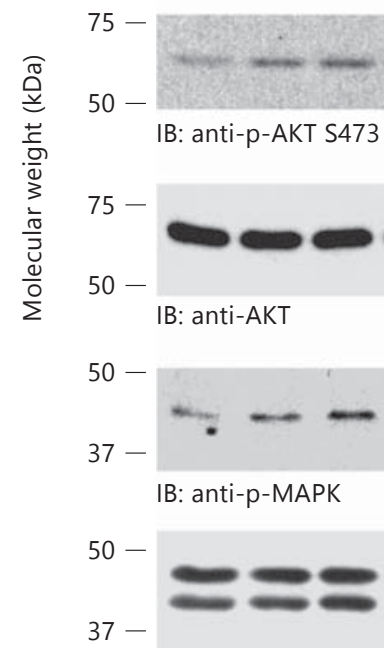

b

IB: anti-MAPK
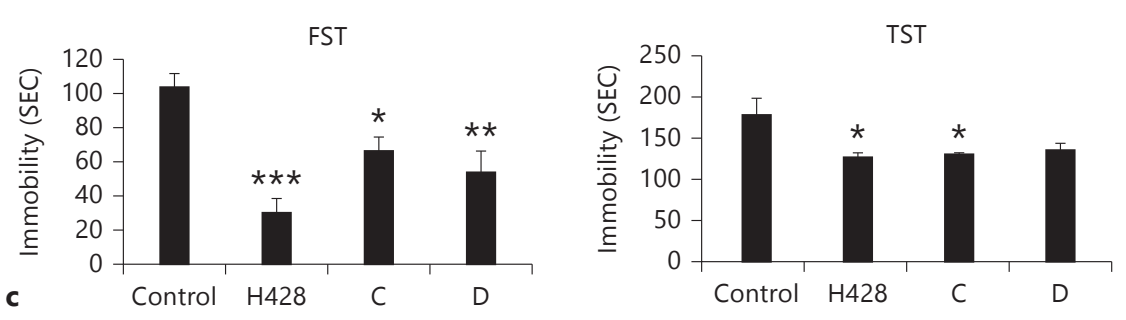

Fig. 5. $\mathbf{b}$ TrkB receptor activation by synthetic compounds $C$ and $\mathrm{D}$ in vivo. The synthetic methylated compounds activate TrkB receptor in mouse brain after oral administration with $1 \mathrm{mg} / \mathrm{kg}$ dose at $2 \mathrm{~h}$. c The methylated derivatives significantly reduce immobility in two antidepressant behavioral assays. Male C57BL/6J mice ( 8 mice/group) were orally administrated by gavage with $5 \mathrm{mg} / \mathrm{kg}$ H428, compounds C and D and vehicle solvent saline for 21 days and subjected to a FST (6 min, immobility recorded in the last 4 min with 2 min preswim). Data are presented as mean \pm SEM. ANOVA revealed a significant difference between vehicle and ei-

Fig. 6. Chronic treatment with methylated derivatives promotes neurogenesis and $\operatorname{TrkB}$ activation in the hippocampus. a Neurogenesis assay via BrdU incorporation. Male C57BL/6J mice were orally administered with $5 \mathrm{mg} / \mathrm{kg}$ of various methylated compounds and vehicle solvent for 21 days and followed by $50 \mathrm{mg} / \mathrm{kg}$ BrdU i.p. Within $2 \mathrm{~h}$, the mice were perfused and brain sections were immunostained with anti-BrdU to monitor the neuronal proliferation phase and DAPI. The positive cells in the dentate gyrus are highlighted by arrows. b Quantitative analysis of the ther of the employed compounds ( $\mathrm{n}=8$, ${ }^{* * *} \mathrm{p}<0.001$ vs. vehicle) (left panel). The mice were subjected to the same treatment and analyzed by TST ( $6 \mathrm{~min}$, immobility recorded in the last $4 \mathrm{~min}$ with 2 min preswim). Data are presented as mean \pm SEM. ANOVA revealed a significant difference between vehicle and either of the employed compounds ( $\mathrm{n}=8,{ }^{* * *} \mathrm{p}<0.001$ vs. vehicle) (right panel). d Locomoter activity assay. Compound D but not compound C or H428 significantly elevated the mice locomotor activity compared to vehicle control after 21 days of chronic treatment. RT = Room temperature. ${ }^{*} \mathrm{p}<0.05{ }^{* *} \mathrm{p}<0.01$. 


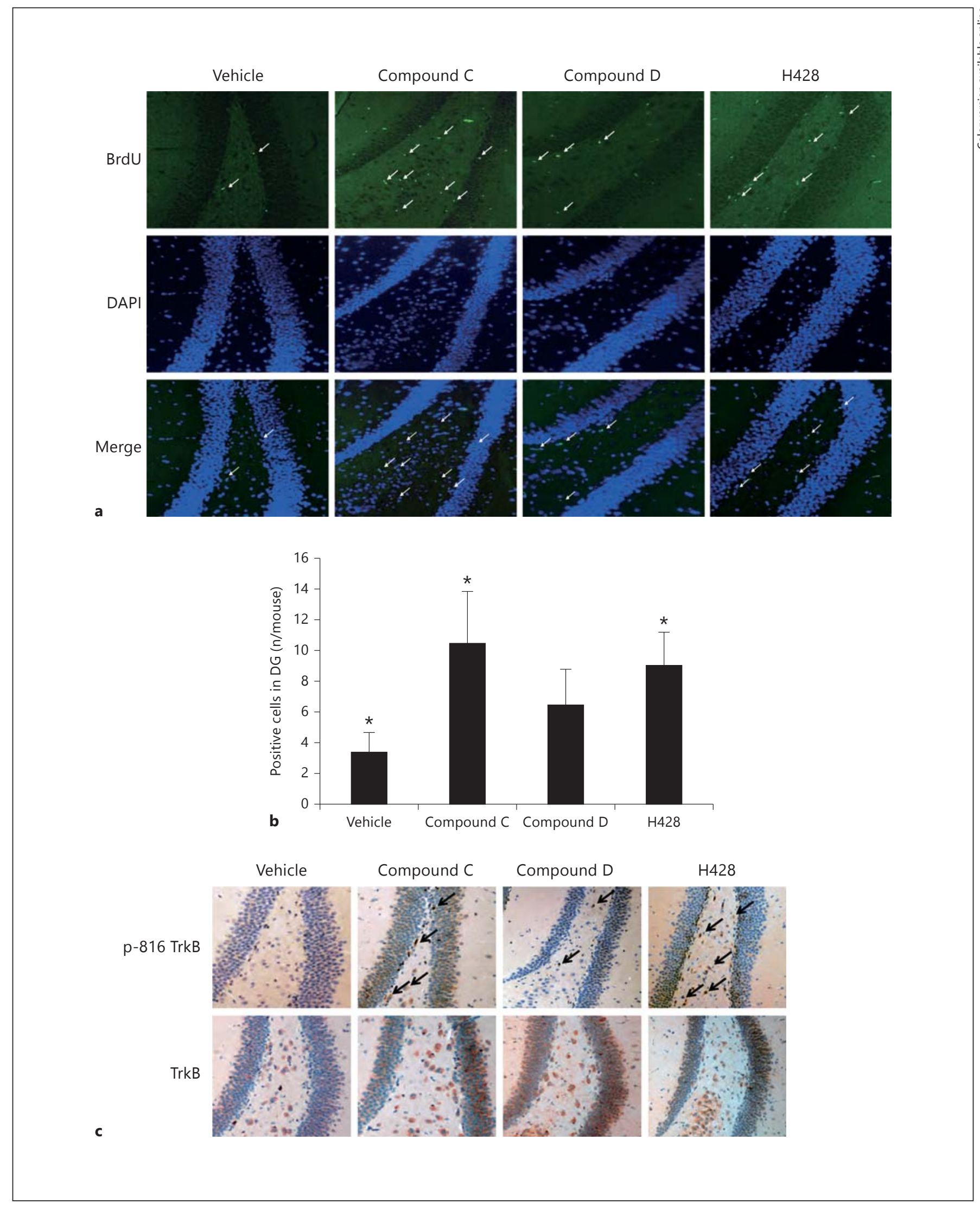


Fig. 7. The schematic model for 7,8-DHF and its methylated metabolites to activate TrkB in brain. The orally administered 7,8DHF is mainly metabolized via glucuronidation and methylation. In the plasma both types of modified metabolites and parent 7,8-DHF were detectable, whereas in brain only 7,8-DHF and 8-mono-methylated metabolite could be demonstrated. Both 7,8DHF and its methylated metabolite provoked TrkB activation in mouse brain. The blockade of COMT transferase inhibits the methylation of 7,8-DHF and reduces the agonistic activity by 7,8 -DHF in mouse brain.

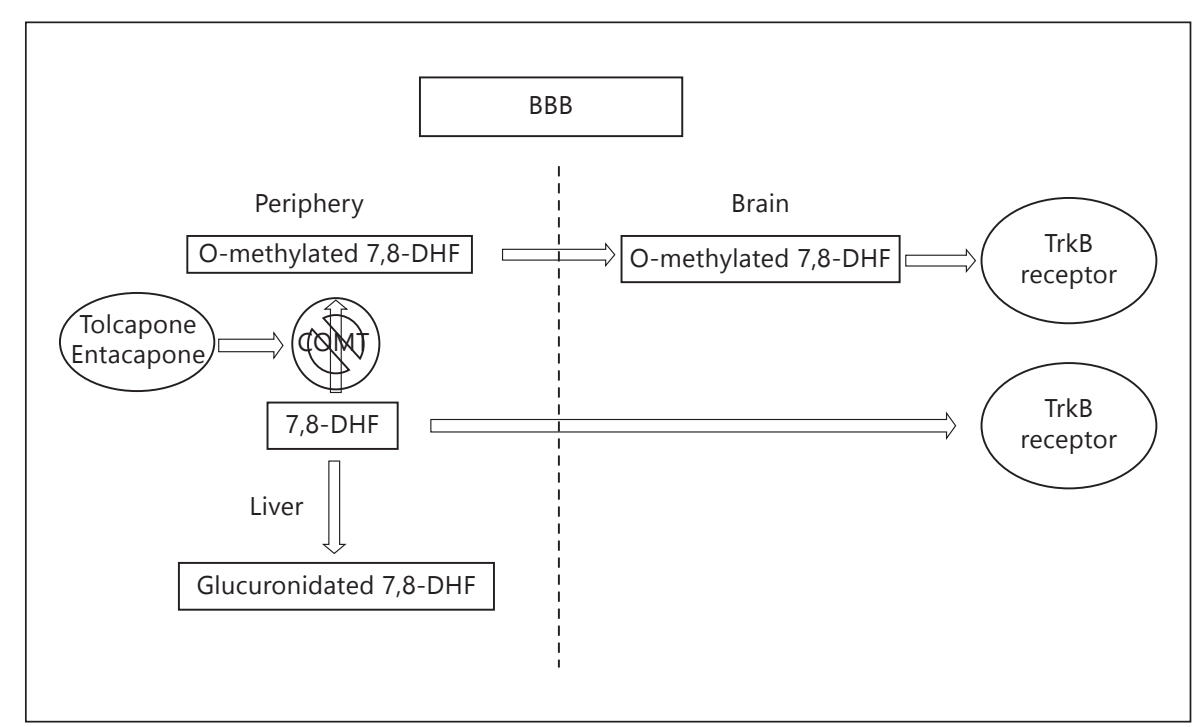

7,8-DHF, it might mainly result from the 8-methoxy7-hydroxyflavone metabolite. Nonetheless, the parent compound concentrations in the brain are approximately 30 -fold higher than those of the methylated metabolite, indicating that the main contribution to triggering TrkB activation results from the parent compound. It is worth noting that $\operatorname{TrkB}$ activation is demonstrable at $4 \mathrm{~h}$ or more in mouse brain after oral dosing of 7,8-DHF [14], suggesting that at later time points, TrkB activation may be predominantly triggered by 7,8-DHF itself. At early time points, such as $1-2 \mathrm{~h}$, the methylated metabolite 8 -methoxy-7-hydroxyflavone may also contribute to TrkB activation in the brain, which is supported by the COMT inhibitor data, and they show partial blockage of the agonistic effect by 7,8-DHF in mouse brain (fig. 4). After oral administration, a portion of $7,8-\mathrm{DHF}$ is metabolized through $\mathrm{O}$-glucuronidation in the circulation system $(\mathrm{O}-$ sulfation on 7,8-DHF was also detected with much lower concentrations in the plasma), lowering its drug exposure in the CNS. The parent drug and methylated metabolites penetrate the $\mathrm{BBB}$, where they both activate the TrkB receptor. Blockage of 7,8-DHF O-mono-methylation via inhibiting COMT diminishes the effect of 7,8-DHF on TrkB activation (fig. 7).

After 7,8-DHF has been administered to animals, it enters the brain, where it may crosstalk with endogenous $\mathrm{BDNF}$ to provoke TrkB receptor activation in the CNS. To explore whether these ligands affect each other's actions on TrkB activation, we monitored TrkB receptor activation in primary neurons by BDNF in the presence or ab- sence of 7,8-DHF. Titration assay showed that BDNF elicited TrkB activation at a concentration of $1-30 \mathrm{nmol} / \mathrm{l}$ and the signals escalated as the doses increased (online suppl. fig. 2A). On the other hand, 7,8-DHF also stimulated TrkB activation in a dose-dependent manner. TrkB phosphorylation was prominent at a concentration of $100 \mathrm{nmol} / 1$ [14, 23]. Remarkably, when $3 \mathrm{nmol} / \mathrm{l} \mathrm{BDNF}$ was mixed with various concentrations of 7,8-DHF, the mixture displayed much higher TrkB phosphorylation signals than when the same dose of BDNF or 7,8-DHF was employed separately (online suppl. fig. 2B). Therefore, there is a synergistic effect between 7,8-DHF and BDNF in provoking TrkB receptor activation. Conceivably, these two molecules bind to different sites on TrkB extracellular domain and trigger an optimal TrkB activation conformation, leading to higher TrkB activation signals than when these molecules interact independently with the receptor.

Levodopa, a precursor of catecholamines, is an important substrate of COMT. COMT inhibitors, like entacapone, protect levodopa from COMT, which prolongs the action of levodopa. Entacapone is a widely used adjunct drug of levodopa therapy. When given with an inhibitor of dopa decarboxylase (carbidopa or benserazide), levodopa is protected further. This 'triple therapy' is becoming a standard in the treatment of Parkinson's disease. Remarkably, we noticed that entacapone or tolcapone pretreatment elicited a higher TrkB phosphorylation baseline than vehicle control, indicating that these COMT inhibitors themselves might somehow induce TrkB activation in mouse brain, concealing the agonistic effect by 
7,8-DHF or the lead compound 4'-DMA-7,8-DHF (fig. 3). It is not surprising that both COMT inhibitors somehow elevate TrkB activation in mouse brain, because both of them contain the catechol group as does 7,8-DHF. In addition, our previous structure-activity relationship study shows that the catechol group in 7,8-DHF mediates its TrkB agonistic effect [14]. We found that 6,7-dihydroxyflavone and 6,7,3'-trihydroxyflavone but not 5,6-dihydroxyflavone or 5,7-dihydroxyflavone possess a TrkB agonistic effect, suggesting that para- and meta-positions of dihydroxy groups on the A ring relative to the ketone group in the $\mathrm{C}$ ring of flavonoids are critical for stimulating the TrkB receptor [14]. These chemical structure characteristics are well in alignment with the backbone structure of tolcapone. Although entacapone does not contain the ketone group attached to the nitrocatechol functional group, it contains the highly conjugated structures, similar to the conjugated $\mathrm{B}$ and $\mathrm{C}$ rings in flavone compounds.

So far, a few small peptides and compounds have been reported to activate the TrkB receptor and might act as TrkB agonists [24, 25]. Nonetheless, these molecules do not fully imitate BDNF or regulate TrkB physiological functions in animals. However, our lead compound 7,8DHF has been extensively demonstrated to mimic BDNF and exert a variety of neurological actions in numerous models including PD, stroke [12], depression [13, 14, 26], learning and memory $[27,28]$. Chronic treatment with 7,8-DHF reveals no demonstrable toxicity, supporting safety at a dose of $5 \mathrm{mg} / \mathrm{kg}$ [14]. In addition, most recently, it has been shown to stimulate the LTP in aged rats through the TrkB receptor [29]. Notably, this compound exhibits therapeutic efficacy in a mouse model of Rett syndrome, which is caused by mutations in $\mathrm{MeCP} 2$, leading to reduced levels of BDNF in the brain [30]. Taken together, this evidence supports the notion that 7,8-DHF indeed mimics BDNF and possesses more prominent physiological activities in various animal models than other reported peptidomimetics or small molecules, supporting the fact that 7,8-DHF is a superior compound, with oral bioavailability, for TrkB agonist drug development.

\section{Acknowledgement}

This work was supported by grants from the National Institute of Health RO1 DC010204 to K. Ye. The authors are grateful to Dr. Obianyo in the lab of Dr. Ye and to Dr. Harish Joshi for critically reading the manuscript.

\section{References}

1 Kaplan DR, Miller FD: Neurotrophin signal transduction in the nervous system. Curr Opin Neurobiol 2000;10:381-391.

2 Huang EJ, Reichardt LF: Trk receptors: roles in neuronal signal transduction. Annu Rev Biochem 2003;72:609-642.

3 Nagappan G, Lu B: Activity-dependent modulation of the BDNF receptor TrkB: mechanisms and implications. Trends Neurosci 2005;28:464-471.

4 Hennigan A, O'Callaghan RM, Kelly AM: Neurotrophins and their receptors: roles in plasticity, neurodegeneration and neuroprotection. Biochem Soc Trans 2007;35:424427.

$\checkmark 5$ Nibuya M, Morinobu S, Duman RS: Regulation of BDNF and trkB mRNA in rat brain by chronic electroconvulsive seizure and antidepressant drug treatments. J Neurosci 1995; 15:7539-7547.

-6 Saarelainen T, Hendolin P, Lucas G, Koponen E, Sairanen M, MacDonald E, Agerman K, Haapasalo A, Nawa H, Aloyz R, Ernfors P, Castren E: Activation of the TrkB neurotrophin receptor is induced by antidepressant drugs and is required for antidepressant-induced behavioral effects. J Neurosci 2003;23: 349-357.
Monteggia LM, Barrot M, Powell CM, Berton O, Galanis V, Gemelli T, Meuth S, Nagy A, Greene RW, Nestler EJ: Essential role of brain-derived neurotrophic factor in adult hippocampal function. Proc Natl Acad Sci USA 2004;101:10827-10832.

-8 Li Y, Luikart BW, Birnbaum S, Chen J, Kwon CH, Kernie SG, Bassel-Duby R, Parada LF: TrkB regulates hippocampal neurogenesis and governs sensitivity to antidepressive treatment. Neuron 2008;59:399-412.

-9 Sahay A, Hen R: Adult hippocampal neurogenesis in depression. Nat Neurosci 2007;10: 1110-1115.

10 Schmidt HD, Duman RS: The role of neurotrophic factors in adult hippocampal neurogenesis, antidepressant treatments and animal models of depressive-like behavior. Behav Pharmacol 2007;18:391-418.

11 Banasr M, Duman RS: Regulation of neurogenesis and gliogenesis by stress and antidepressant treatment. CNS Neurol Disord Drug Targets 2007;6:311-320.
12 Jang SW, Liu X, Yepes M, Shepherd KR, Miller GW, Liu Y, Wilson WD, Xiao G, Blanchi B, Sun YE, Ye K: A selective TrkB agonist with potent neurotrophic activities by 7,8-dihydroxyflavone. Proc Natl Acad Sci USA 2010; 107:2687-2692.

13 Blugeot A, Rivat C, Bouvier E, Molet J, Mouchard A, Zeau B, Bernard C, Benoliel JJ, Becker C: Vulnerability to depression: from brain neuroplasticity to identification of biomarkers. J Neurosci 2011;31:12889-12899.

14 Liu X, Chan CB, Jang SW, Pradoldej S, Huang J, He K, Phun LH, France S, Xiao G, Jia Y, Luo HR, Ye K: A synthetic 7,8-dihydroxyflavone derivative promotes neurogenesis and exhibits potent antidepressant effect. J Med Chem 2010;53:8274-8286.

15 LeWitt PA: Subcutaneously administered apomorphine: pharmacokinetics and metabolism. Neurology 2004;62:S8-S11.

16 Cryan JF, Mombereau C, Vassout A: The tail suspension test as a model for assessing antidepressant activity: review of pharmacological and genetic studies in mice. Neurosci Biobehav Rev 2005;29:571-625. 
17 Steru L, Chermat R, Thierry B, Simon P: The tail suspension test: a new method for screening antidepressants in mice. Psychopharmacology (Berl) 1985;85:367-370.

18 Bonifacio MJ, Palma PN, Almeida L, Soaresda-Silva P: Catechol-O-methyltransferase and its inhibitors in Parkinson's disease. CNS Drug Rev 2007;13:352-379.

19 Mannisto PT, Tuomainen P, Tuominen RK: Different in vivo properties of three new inhibitors of catechol O-methyltransferase in the rat. Br J Pharmacol 1992;105:569-574.

20 Kaakkola S, Wurtman RJ: Effects of catecholO-methyltransferase inhibitors and L-3,4-dihydroxyphenylalanine with or without carbidopa on extracellular dopamine in rat striatum. J Neurochem 1993;60:137-144.

-21 Learmonth DA, Vieira-Coelho MA, Benes J, Alves PC, Borges N, Freitas AP, da-Silva PS: Synthesisof 1-(3,4-dihydroxy-5-nitrophenyl)2-phenyl-ethanone and derivatives as potent and long-acting peripheral inhibitors of catechol-O-methyltransferase. J Med Chem 2002; 45:685-695.
22 Scharfman H, Goodman J, Macleod A, Phani S, Antonelli C, Croll S: Increased neurogenesis and the ectopic granule cells after intrahippocampal BDNF infusion in adult rats. Exp Neurol 2005;192:348-356.

23 Gupta VK, You Y, Li JC, Klistorner A, Graham SL: Protective effects of 7,8-dihydroxyflavone on retinal ganglion and RGC-5 cells against excitotoxic and oxidative stress. J Mol Neurosci 2013;49:96-104.

24 Fletcher JM, Hughes RA: Modified low molecular weight cyclic peptides as mimetics of BDNF with improved potency, proteolytic stability and transmembrane passage in vitro. Bioorg Med Chem 2009;17:2695-2702.

25 Massa SM, Yang T, Xie Y, Shi J, Bilgen M, Joyce JN, Nehama D, Rajadas J, Longo FM: Small molecule BDNF mimetics activate TrkB signaling and prevent neuronal degeneration in rodents. J Clin Invest 2010;120: 1774-1785.
26 Jang SW, Liu X, Chan CB, France SA, Sayeed I, Tang W, Lin X, Xiao G, Andero R, Chang Q, Ressler KJ, Ye K: Deoxygedunin, a natural product with potent neurotrophic activity in mice. PLoS One 2010;5:e11528.

27 Choi DC, Maguschak KA, Ye K, Jang SW, Myers KM, Ressler KJ: Prelimbic cortical $\mathrm{BDNF}$ is required for memory of learned fear but not extinction or innate fear. Proc Natl Acad Sci USA 2010;107:2675-2680.

28 Andero R, Heldt SA, Ye K, Liu X, Armario A, Ressler KJ: Effect of 7,8-dihydroxyflavone, a small-molecule TrkB agonist, on emotional learning. Am J Psychiatry 2011;168:163-172.

29 Zeng Y, Tan M, Kohyama J, Sneddon M, Watson JB, Sun YE, Xie CW: Epigenetic enhancement of BDNF signaling rescues synaptic plasticity in aging. J Neurosci 2011;31:1780017810.

30 Johnson RA, Lam M, Punzo AM, Li H, Lin BR, Ye K, Mitchell GS, Chang Q: 7,8-Dihydroxyflavone (7,8-DHF) exhibits therapeutic efficacy in a mouse model of Rett syndrome. J Appl Physiol 2012;112:704-710. 